This a non-peer reviewed preprint submitted to EarthArXiv:

\title{
An image- and BET-based Monte-Carlo approach to determine mineral accessible surface areas in sandstones
}

Jin Ma, Geothermal Energy $\&$ Geofluids Group, Department of Earth Sciences (D-ERDW), ETH-Zürich, CH-8092, Switzerland. email: majin@ethz.ch

Martin O. Saar, Geothermal Energy $\&$ Geofluids Group, Department of Earth Sciences (D-ERDW), ETH-Zürich, CH-8092, Switzerland. email: saarm@ethz.ch

Xiang-Zhao Kong, Geothermal Energy 8 Geofluids Group, Department of Earth Sciences (D-ERDW), ETH-Zürich, CH-8092, Switzerland. email: xkong@ethz.ch 


\title{
An image- and BET-based Monte-Carlo approach to determine mineral accessible surface areas in sandstones
}

\author{
Jin Ma, Martin O. Saar, Xiang-Zhao Kong* \\ Geothermal Energy and Geofluids Group, Department of Earth Sciences, ETH-Zürich, CH-8092, \\ Switzerland
}

\begin{abstract}
Accessible surface areas (ASAs) of individual rock-forming minerals exert a fundamental control on how minerals react with formation fluids. However, due to lacking adequate quantification methods, determining the ASAs of specific minerals in a multi-mineral rock at the appropriate scale still remains difficult. Whole-rock Brunauer-Emmett-Teller (BET) measurements at atomic scales cannot account for the variability in ASAs of individual minerals, while image-based methods are inherently limited by the image pixel/voxel resolution. Here, we present a novel joint method that overcomes the aforementioned limitations by appropriately downscaling individual image-based ASAs with the support of a Monte-Carlo algorithm and BET measurements. This joint method consists of three steps: 1) segmentation of pore/mineral phases, 2) calculation of image-based contour surface areas, and 3) determination of a resolution scaling factor (SF). Superior to conventional segmentation methods, which are based on scanning electron microscopy (SEM) images alone, here, the segmentation threshold is independently constrained by both pore size distribution measurements and rock chemical composition analyses. Most importantly, the introduction of an SF, obtained by probability mapping, using a Monte-Carlo algorithm, accounts for mineral surface roughness variations, provided by the BET measurements during the determination of the image-based ASAs. We apply this joint method to a sandstone specimen and confirm the validity and accuracy of the obtained results with our reactive flow-through experiment, reported in Ma et al. (2019). We conclude that our novel method can effectively downscale the imagebased ASAs to the atomic BET resolution with minimum assumptions, providing a valuable tool to improve the calculation of fluid-mineral reactions.

Keywords:

Accessible Surface Area, Mineral-specific, Monte-Carlo, Image Resolution, Surface Roughness, Downscaling
\end{abstract}

\section{Introduction}

Natural or engineered geological systems, such as enhanced geothermal systems (EGS) (Althaus and Edmunds, 1987, Pandey et al., 2015) and carbon capture, utilization, and storage (CCUS) systems (Xu et al., 2003; Gaus, 2010; Luhmann et al.

\footnotetext{
${ }^{*}$ Corresponding author at: Geothermal Energy and Geofluids Group, Department of Earth Sciences, ETH-Zürich, CH-8092, Switzerland E-mail address: xkong@ethz.ch (X.-Z. Kong)
} 
2014; Tutolo et al., 2015; Saar et al., 2012; Adams et al., 2015; Garapati et al., 2015), often involve fluid-rock reactions. These reactions could lead to mineral dissolution and/or precipitation which may cause dramatic changes in the reservoir hydraulic properties (Nogues et al., 2013; Cai et al., 2009, Cheshire et al., 2016; Yasuhara et al. 2017; Voskov et al., 2017). A key parameter, controlling the rates of these surface reactions (i.e. mineral dissolution/precipitation), is the accessible surface area (ASA) of individual minerals. Here the ASA of a mineral is defined as the mineral-specific surface area that is physically exposed to the pore space and thus the pore fluids. Accurate estimation of the mineral-specific ASAs plays a critical role in chemical interpretations of field and laboratory observations, and provides an essential input for reactive transport modelling, involving fluid-rock reaction kinetics (Luhmann et al. 2014; Beckingham et al., 2016; Ma et al., 2019).

However, the mineral-specific ASAs in a multi-mineral system is often poorly constrained (Bourg et al. 2015) due to the lack of adequate surface area quantification methods. In general, the ASA of a porous rock is estimated by: (1) geometric calculations, including various grain models (Gunter et al., 2000; Xu et al., 2004; Cubillas et al., 2005; White et al., 2005; Knauss et al., 2005) and image-based pixel/voxel surface area determinations (Peters, 2009; Landrot et al., 2012; Ellis and Peters, 2016; Lai et al., 2015; Beckingham et al., 2016, 2017; Kweon and Deo, 2017), (2) gas absorption measurements, based on the Brunauer-Emmett-Teller (BET) theory (Brunauer et al. 1938; Dogan et al., 2006), and (3) geochemical modeling of batch or flowthrough reactive experiments (Noiriel et al., 2009; Luhmann et al., 2014). Surface area calculations from geometrical shapes or scanned images can usually account for the heterogeneous distribution of mineral ASAs, however, at the expense of preserving structural details, such as grain surface roughness and clay mineral features, due to requiring an assumption of simple grain shapes or limitations in image resolution (Qin and Beckingham, 2018). On the other hand, BET measurements provide a material's total surface area at atomic-scale resolution, sufficiently resolving surface roughness, which cannot be captured by common image-based analyses. Often, the mineral-specific ASAs are calculated as the product of the BET-measured value and the mass/volume fraction of that mineral, disregarding the actual geometry of the pore space and minerals. Furthermore, ASAs estimated by reaction experiments usually depend on the experiment conditions and are thus difficult to extrapolate to other conditions. For example, heterogeneous flow properties, such as the velocity field, fluid mixing, and varying diffusion rates may introduce significant errors when estimating ASAs (Li et al., 2006).

To overcome the aforementioned limitations in ASA determination, combinations of the aforementioned methods have been explored (Peters, 2009; Lai et al., 2015; Beckingham et al., 2016, 2017; Kweon and Deo, 2017). For example, a scaling factor (SF) has been proposed to amend the difference between the pixel/voxel-based contour surface area and the BET-measured values. Knauss et al. (2005) suggested an 'edge factor' of 10 for sheet silicate minerals, while Peters (2009) suggested an SF with a range of 3-13 for clay minerals, depending on the clay content. Lai et al. (2015) proposed a BET/image-based roughness SF evaluation model, which is em- 
ployed later by Kweon and Deo (2017), assuming that the SF of clay minerals is 10 times that of non-clay minerals. Beckingham et al. (2016) took another approach in estimating ASAs in a multi-mineral sandstone, where ASAs of non-clay minerals are calculated directly, based on the digitized mineral contours, given by scanning electron microscopy (SEM) images, while the BET-measured values from the literature are taken as the ASAs for clay minerals. These approximations and simplifications highlight the unsatisfactory situation of mineral-specific ASA determination.

In this study, we develop a Monte-Carlo approach to effectively determine ASAs of individual minerals in a multi-mineral sandstone specimen. The paper begins with thorough characterizations of the properties of the sandstone, such as the mineralogy, pore/mineral distribution, and the total surface area, employing various laboratory measurements (Section 2). These properties are later used as inputs, or benchmarks, in Section 3, where the image-based Monte-Carlo approach is described in detail. Finally, the impact of the SEM image resolution, the segmentation threshold, and the sample size of the Monte-Carlo calculation on the determined ASA is discussed in Section 4. The calculated dolomite ASA is successfully used for a reactive flowthrough experiment conducted on the same sandstone in another study (Ma et al. 2019).

\section{Material}

The rock specimens, used in this study, are sandstone cores, taken at a depth of $954.6 \mathrm{~m}$ from a geothermal well, Vydmantai-1, at the southeast end of the Baltic Sea in Lithuania. The Vydmantai geothermal site was one of the project sites in the DESTRESS project (www.destress-h2020.eu), entitled "Demonstration of soft stimulation treatments of geothermal reservoirs". Although this sandstone geothermal site has been stimulated by acid injection, it was not possible to enhance the reservoir injectivity/productivity (Brehme et al., 2018). One of the objectives of this study is to identify parameters to facilitate the understanding of acid stimulation geochemical processes. Transmitted light microscopy observations show that the grains in the sandstone are well-rounded, fine to very fine grains (sizes of $65 \mu \mathrm{m}-250 \mu \mathrm{m}$ ).

\subsection{Pore space characterization}

To quantify the mineral ASAs, we first need to map the pore space (Section 3.1) of the sandstone specimen. We scan a $35 \mu \mathrm{m}$-thick thin section of the specimen $(29 \mathrm{~mm} \times 22 \mathrm{~mm}$ ), employing a backscattered electron (BSE) scan (Jeol JSM-6390 LA SEM together with a BSE detector in the Electron Microscopy Lab at ETH Zürich). To achieve a $1.2 \mu \mathrm{m}$-resolution, the SEM-BSE scanning is continuously performed, using $10 \times 10$ scanning windows, at an electron accelerating voltage of $15 \mathrm{keV}$ and a working distance of $10 \mathrm{~mm}$. Using ImageJ, these $10 \times 10$ coherent gray-scale images are then stitched together to generate a full image of $9474 \times 6947$ $\operatorname{pixel}^{2}(11.37 \mathrm{~mm} \times 8.34 \mathrm{~mm})$, as shown in Figure $2 a$. This SEM-BSE image serves as the base to determine the ASA, the porosity, and the pore size distribution (PSD). The later two are then compared to laboratory measurements as stated below. 
The porosity of the sandstone specimen is determined on a cylindrical core with a bulk volume of $19.7 \pm 0.1 \mathrm{ml}$ (diameter $=25.4 \pm 0.1 \mathrm{~mm}$ and length $=39.0 \pm 0.1 \mathrm{~mm}$, measured by a Vernier calliper). The total solid volume of the core is measured, employing a Micromeritics AccuPyc II 1340 Pycnometer in the Rock Deformation Laboratory at ETH Zürich. After 16 purges of Helium at a temperature of $25.14{ }^{\circ} \mathrm{C}$, the measurement yields a solid volume of $15.441 \pm 0.004 \mathrm{ml}$. Then, a porosity of $21.9 \pm 0.4 \%$ can be calculated from the ratio between the pore volume (subtracting the total solid volume from the bulk volume) and the bulk volume.

The PSD of the specimen is obtained, employing mercury intrusion porosimetry. The PSD measurement is carried out at a temperature of $22.6{ }^{\circ} \mathrm{C}$ and a maximum pressure of $400 \mathrm{MPa}$, using the Porotec Pascal 140 and 440 (with a detection size range of $2 \mathrm{~nm}-100 \mu \mathrm{m}$ in diameter) in the IGT Claylab at ETH Zürich. The measured PSD results are later smoothed by a 10-point running averaging filter and reported as the blue solid line in Figure 3(c). Micro-computed tomography (Micro-CT) is also employed to obtain a 3D geometric representation of the rock specimen. Images with $1.1 \mu \mathrm{m}$-resolution are acquired, using a voltage of $100 \mathrm{kV}$ and a current of $19.7 \mu \mathrm{A}$, performed by Thermal Fisher HeliScan. The PSD of the reconstructed 3D image is analyzed using a Proprietary software developed by Scanco Medical AG (Hildebrand and Rüegsegger, 1997), and plotted as the black-dashed line in Figure 3(c). Both PSD results indicate that the majority of the pore volume $(>97 \%)$ is provided by pores with sizes between $0.1 \mu \mathrm{m}$ and $70 \mu \mathrm{m}$, displaying a frequency peak at a pore size of $\sim 20 \mu \mathrm{m}$. The PSD measurements aim to independently facilitate the threshold determination during pore segmentation, based on the SEM-BSE image (Section 3.1).

\subsection{Mineralogy characterization}

In addition to the SEM-BSE image, the sandstone specimen is imaged by employing SEM - Energy Dispersive X-Ray Spectroscopy (EDS) to quantify the ASAs of each mineral (Section 3.2). The minerals of the sandstone specimen are identified using the quantitative SEM analysis that is carried out with a Jeol JSM-6390 LA SEM and an Energy Dispersive X-Ray Spectroscopy (EDS) system (Thermo Fisher NORAN NSS7, with a $30 \mathrm{~mm}^{2}$ Silicon-drift detector) in the High-pressure Lab at ETH Zürich. During the quantitative SEM-EDS analysis, the same $35 \mu \mathrm{m}$-thick thin section $(11.37 \mathrm{~mm} \times 8.34 \mathrm{~mm})$ of the sandstone specimen is divided into $5 \times 5$ scanning windows. In each scanning window, the detected elements are mapped with different colors in the SEM image at a pixel resolution of $2.4 \mu \mathrm{m}$, using the element $\mathrm{X}$-ray spectra at $20 \mathrm{sec} \times 50$ frames (1000 counts). Using ImageJ, the resultant $5 \times 5$ coherent images are stitched to produce a full SEM-EDS image with $4737 \times 3474$ pixels (Figure 2b). The following six minerals are identified: quartz, dolomite, Kfeldspar, kaolinite, muscovite, and ilmenite. The chemical formula of each mineral is determined by SEM quantitative chemical analysis on the same $35 \mu \mathrm{m}$-thick thin section. Each mineral is examined at 5-10 different spots, yielding its mineral formula with averaged element ratios (Table 1).

In order to assist mineral segmentation, discussed in Section 3.2, the element content of the specimen is independently analyzed on fusion beads. To ensure represen- 
Table 1: Minerals, their chemical formulae and weight percentages, identified by SEM image processing. The mineral densities are from webmineral: http://webmineral.com/

\begin{tabular}{llll}
\hline Mineral & Chemical formula & $\begin{array}{l}\text { Density } \\
\left(\mathrm{g} / \mathrm{cm}^{3}\right)\end{array}$ & $\begin{array}{l}\text { Fraction } \\
(\text { wt.\%) }\end{array}$ \\
\hline Quartz & $\mathrm{SiO}_{2}$ & 2.62 & 58.38 \\
Dolomite & $\mathrm{Ca}_{1.05} \mathrm{Mg}_{0.75} \mathrm{Fe}_{0.2}\left(\mathrm{CO}_{3}\right)_{2}$ & 2.84 & 15.78 \\
K-feldspar & $\mathrm{KAlSi}_{3} \mathrm{O}_{8}$ & 2.56 & 11.15 \\
Muscovite & $\mathrm{K}_{0.5} \mathrm{MgFe}_{0.4} \mathrm{Al}_{1.2}\left(\mathrm{AlSi}_{3} \mathrm{O}_{10}\right)(\mathrm{OH})_{2}$ & 2.82 & 6.07 \\
Kaolinite & $\mathrm{Al}_{1.8} \mathrm{Si}_{2.2} \mathrm{O}_{5}(\mathrm{OH})_{4}$ & 2.60 & 7.93 \\
Ilmenite & $\mathrm{Ti}_{5} \mathrm{Fe}_{2} \mathrm{O}_{12}$ & 4.72 & 0.69 \\
\hline
\end{tabular}

Table 2: Weight percentages of the major elements in the rock specimen, obtained independently from measurements using XRF, LA-ICP-MS, and SEM image processing.

\begin{tabular}{llll}
\hline Elements & XRF (wt.\%) & ICP-MS (wt.\%) & SEM (wt.\%) \\
\hline $\mathrm{Si}$ & 33.99 & 35.54 & 35.19 \\
$\mathrm{Al}$ & 2.76 & 3.44 & 3.62 \\
$\mathrm{Fe}$ & 1.41 & 1.45 & 1.45 \\
$\mathrm{Mg}$ & 1.93 & 1.93 & 1.94 \\
$\mathrm{Ca}$ & 3.35 & 4.09 & 3.60 \\
$\mathrm{~K}$ & 1.60 & 2.04 & 1.93 \\
$\mathrm{Ti}$ & 0.22 & 0.26 & 0.31 \\
\hline
\end{tabular}

tative measurements, $24.4 \mathrm{~g}$ of the sandstone specimen is crushed into a fine powder, from which $1.5 \mathrm{~g}$ are mixed with Lithium-Tetraborate at a ratio of 1:5 to produce the fusion beads. The mixture is processed for the loss on ignition (LOI) measurement at $1050{ }^{\circ} \mathrm{C}$ for 2 hours and then melted at $1080{ }^{\circ} \mathrm{C}$, using the PANalytical Eagon 2 fusion instrument. We used both X-ray fluorescence (XRF, PANalytical AXIOS) and Laser Ablation Inductively Coupled Plasma Mass Spectrometry (LA-ICP-MS, 193 nm ArF-Excimer laser ablation system coupled with Perkin Elmer 6100 DRC quadrupole ICP-MS) to analyze the element weight percentage of the fusion beads in the Institute of Geochemistry and Petrology at ETH Zürich. Weight percentages of 10 major oxides and 21 trace elements are determined during the XRF analysis, using approximately 30 certified international standards for calibrations. We measured weight percentages of 64 elements/isotopes during the LA-ICP-MS analysis, using BCR-2 as the standard material for quality control. The weight percentages of the major elements are listed in Table 2, showing consistency among all analyses.

\subsection{Surface area characterization}

The mass-specific surface area (SSA) of the rock specimen is measured employing a gas adsorption method, based on the Brunauer-Emmett-Teller (BET) theory. The measurements are conducted using a surface area analyzer, TriStar 3000, in the Particle Technology Laboratory at ETH Zürich. Before the BET measurements, small pieces of the rock specimen (in total $3.6 \mathrm{~g}$ ) are vacuumed at $150{ }^{\circ} \mathrm{C}$ for about 
15 hours. During the BET measurements, nitrogen is used as the adsorption gas at a temperature of $77.3 \mathrm{~K}$. A 5-point method is adopted, yielding a bulk SSA of the specimen of $1.6700 \pm 0.0019 \mathrm{~m}^{2} / \mathrm{g}$, with a correlation coefficient of 0.99995 . This bulk SSA later serves as the benchmark and the objective function (Section 3.4).

\section{Methodology}

The goal of this study is to develop a joint method that can accurately determine the ASA for each individual mineral in a multi-mineral system. This joint method is illustrated by the flow chart in Figure 1, with detailed descriptions in the sub-sections that follow.

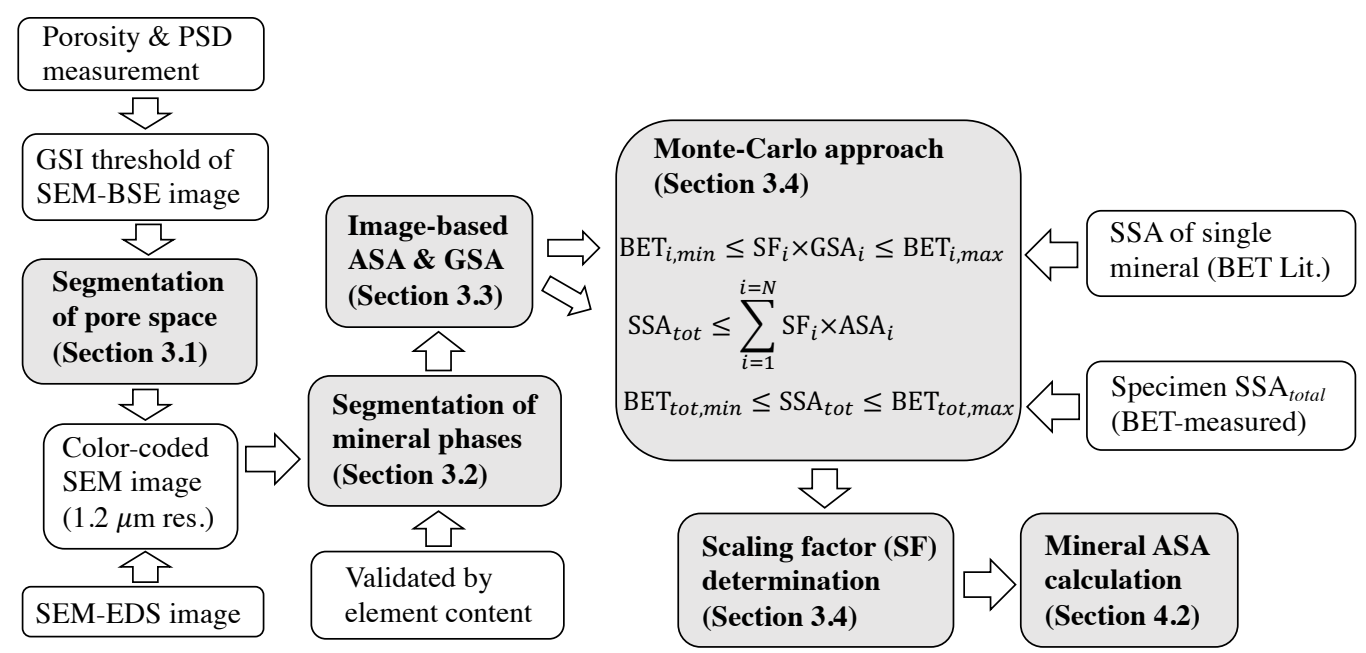

Figure 1: Flow chart of the proposed joint method. The gray boxes represent the main steps of the joint method. The white boxes describe the supporting measurements/validations for the main steps.

\subsection{Segmentation of the pore space}

The gray-scale index (GSI) in the SEM-BSE image varies from 0 to 255, depending on the mean atomic number. Pixels with a smaller GSI appear darker in the SEM-BSE image, depicting a less dense mineral (or pores), whereas pixels with a larger GSI appear brighter in the SEM-BSE image, indicating a denser mineral. The logarithmic histogram of the GSI of the SEM-BSE image (1.2 $\mu \mathrm{m}$ resolution) is shown as a dark blue curve in Figure 3 a. The first peak of the GSI histogram plots at 0, representing the pore space. The second GSI histogram peak plots at 130-150, representing quartz (the mineral with the smallest mean atomic number in this sandstone specimen). To note, the GSIs between these two peaks come from the transition pixels between the pores and the solids, depending on the image resolution.

This wide range of GSI along the pore-solid boundaries poses a challenge in the segmentation of the pore space and thus the determination of the porosity as well as 
the PSD and the ASA analyses. Therefore, an appropriate GSI threshold needs to be determined to separate between pore space and solid. It is well-known that the image resolution determines the covered area of a single pixel, which subsequently affects the GSI value of that pixel in the scanned sample. In other words, the GSI distribution, especially for the pore-solid pixels, depends on the image resolution. To illustrate the effect of image resolution on GSI distribution, we re-size the SEMBSE image (Figure 2 2 ) from the original resolution of $1.2 \mu \mathrm{m}$ to lower resolutions (down to $10.8 \mu \mathrm{m}$ ). Although the locations of the peaks in the GSI histogram remain unchanged, the differences in GSI frequency are bigger at the two ends of the spectrum, due to the loss of pixel features after the resizing of the image (Figure 3a). Most importantly, as the image resolution is lowered, the GSI frequency of the first peak (GSI=0) decreases and that of the pore-solid boundary pixels $(2 \leq$ GSI $\leq$ 130) increases. These changes directly influence the pore space segmentation. To obtain an appropriate GSI threshold for the pore segmentation, we examine four GSIs (GSI $=10,15,20$ and 25) as the thresholds to binarize the original and the re-sized images. According to the principle of stereology (Weibel, 1969), the 2D area density $\left(\mathrm{m}^{2} / \mathrm{m}^{2}\right)$ is equivalent to the $3 \mathrm{D}$ volume density $\left(\mathrm{m}^{3} / \mathrm{m}^{3}\right)$. The pore fraction of the specimen can thus be approximated by the $2 \mathrm{D}$ area density, given here by the ratio of the pore pixels to the total image pixels. We compute the pore fractions of each binary image with different resolutions and thresholds and show the results in Figure 3(b). For the same GSI threshold, the pore fraction decreases as the image resolution decreases. Similar relationships between the accumulative pore volume fraction and the detectable pore size at a certain pressure are found in mercury intrusion measurements. Assuming that pores smaller than a certain resolution do not contribute to the detectable pore fraction, using the PSD data (Figure 3c), we can calculate the pore fraction for each desired resolution (Figure 3b). This calculation agrees well with the pore fraction curve obtained by using a GSI threshold of 20 . Therefore, we use 20 as the GSI threshold to generate a binary SEM-BSE image for pore segmentations. Employing the ImageJ Xlib plugin, which measures the segmented pore size with a circle, we obtain a continuous PSD calculation (Figure 3r). A good agreement between the porosimetry-measured PSD and the calculated PSD can be observed, when the pore size is smaller than $\sim 20 \mu \mathrm{m}$. However, a mismatch between the two PSDs is given for pore sizes larger than $\sim 20 \mu \mathrm{m}$. This mismatch might be due to the differences in measuring 2D and 3D pore sizes (Münch and Holzer, 2008, Latief, 2016). To confirm our hypothesis, we use a 3D micro-CT data set, with a resolution of $1.1 \mu \mathrm{m}$, to calculate another PSD (Figure 3c). It is clear that the porosimetry-measured PSD agrees well with the PSD obtained from the 3D micro-CT data set. Nonetheless, using the porosimetry-measured PSD, we can independently determine a GSI threshold for the pore segmentation. To the best of our knowledge, this method to determine GSI threshold has never been reported.

\subsection{Segmentation of the mineral phases}

We segment individual minerals in the color-coded SEM-EDS image to obtain a set of distribution maps of each mineral at a resolution of $2.4 \mu \mathrm{m}$. We then register 


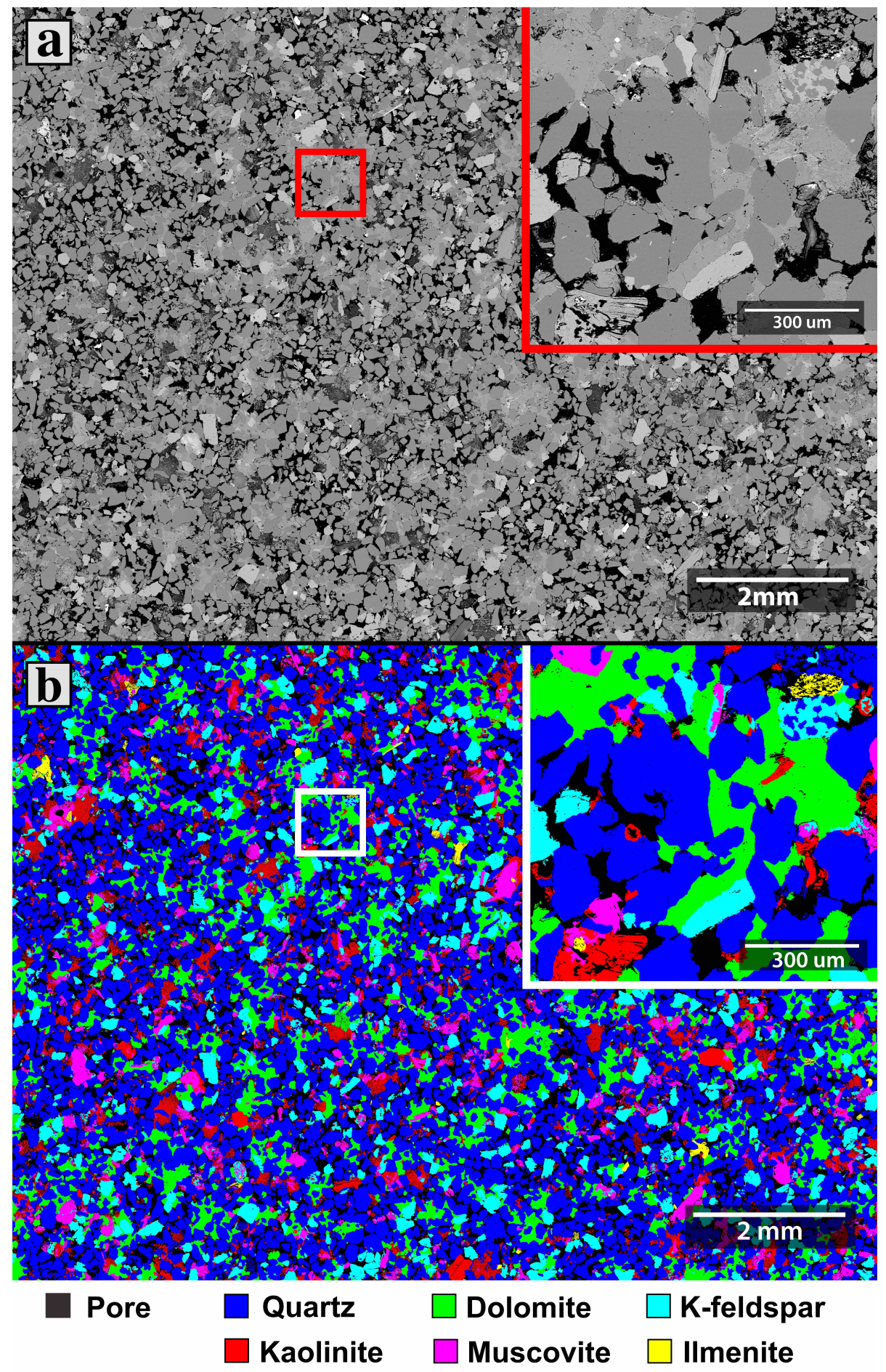

Figure 2: (a) Gray scale SEM-BSE image at a resolution of $1.2 \mu \mathrm{m}$ and (b) the color-coded mineral distribution map at a resolution of $1.2 \mu \mathrm{m}$, registered with the SEM-EDS image. A $5 \times$ enlargement of the rectangular box is inserted in the top-right of each figure. 

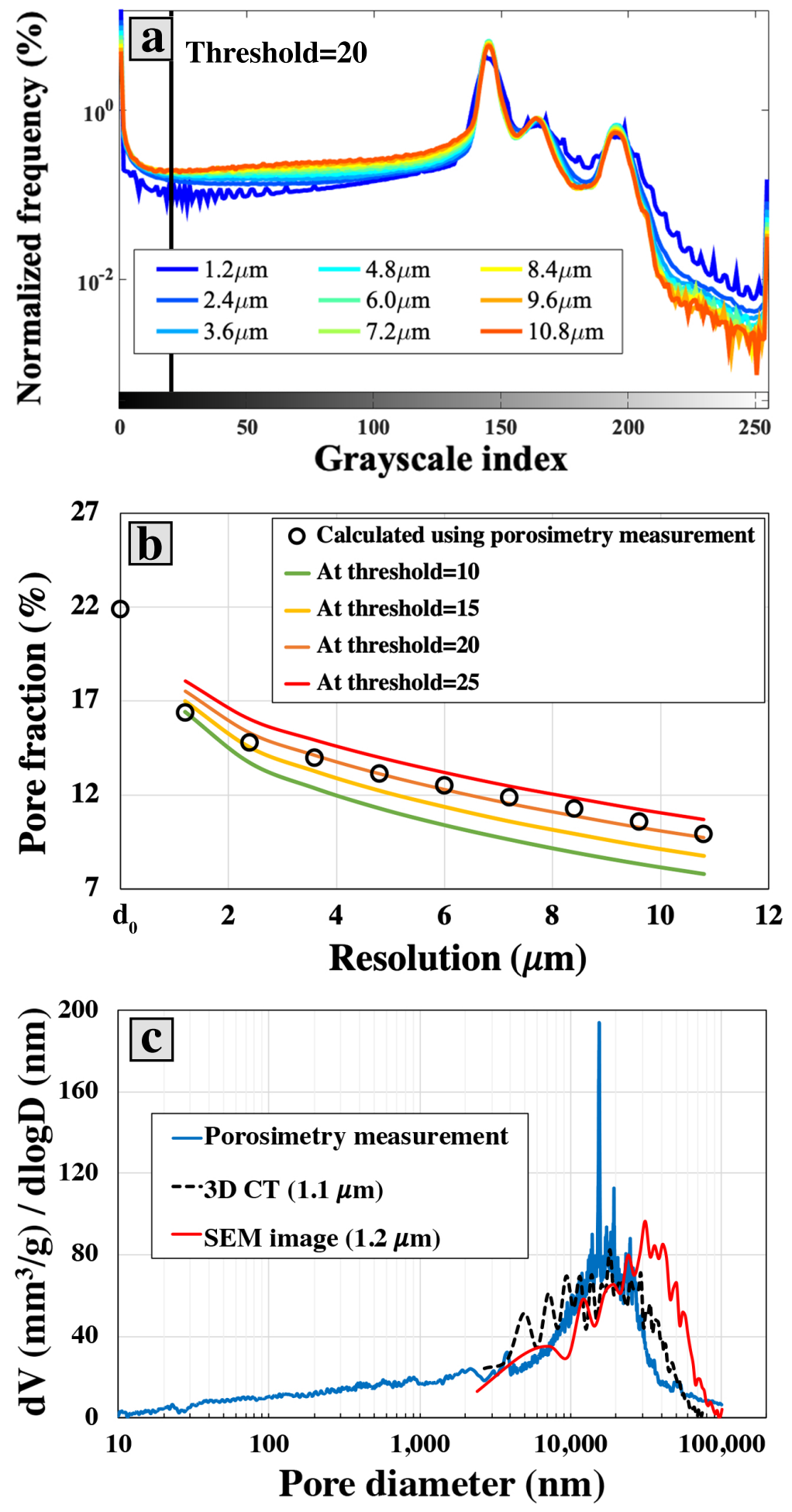

Figure 3: (a) Histograms at a logarithmic scale of the gray-scale indexes (GSI) of the SEM-BSE image at various resolutions. (b) The effect of image resolution on pore fractions at different GSI thresholds, where $d_{0}$ is the reference resolution of the porosimetry measurement. The black circles represent the pore fractions calculated using mercury porosimetry data. (c) Comparison of pore size distributions from mercury intrusion porosimetry, SEM-BSE image analysis $(1.2 \mu \mathrm{m})$, and 3D micro-CT analysis $(1.1 \mu \mathrm{m})$. 
the higher resolution $(1.2 \mu \mathrm{m})$ pore geometry map (the SEM-BSE image) with the mineral distribution maps (the SEM-EDS image) to deliver a mineral map with a resolution of $1.2 \mu \mathrm{m}$ (Figure $2 \mathrm{~b}$ ). Note that during the image registration, because of the resolution difference, there are residual gaps between some of the mineral grains. These gaps are then filled with the closest mineral in the map. Later on this mineral map is referred to as the color-coded SEM image.

Similar to the pore fraction calculation, the volume fraction of each mineral is obtained based on the principle of stereology (Weibel, 1969). We calculate the volume fraction of each mineral by dividing the sum of the corresponding mineral pixels by the total image pixels. Then, we determine the mass fraction of each mineral as the product of its volume fraction and its typical density (Table 1). Additionally, we calculate the element weight percentages based on mineral chemical formulae (Table 1), mineral volume fractions, and mineral densities. The calculated element weights agree well within the two independent measurements using the XRF and LA-ICP-MS analyses (Table 2).

\subsection{Image-based surface areas}

With the obtained color-coded SEM image, we calculate the perimeter density $\left(\mathrm{m} / \mathrm{m}^{2}\right)$ for each mineral phase. Based on the principle of stereology (Weibel, 1969), the mineral SSA $\left(\mathrm{m}^{2} / \mathrm{g}\right)$ can be estimated as:

$$
\mathrm{SSA}=\frac{4}{\pi \rho b} P
$$

where $4 / \pi$ is the stereological bias correction factor, $\rho$ is the rock/mineral density $\left(\mathrm{g} / \mathrm{m}^{3}\right), b$ is the pixel size $(\mathrm{m} / \mathrm{pixel})$, and $P$ is the perimeter density in the $2 \mathrm{D}$ image (pixel $\left./ \mathrm{pixel}^{2}\right)$. During the calculation of the image-based geometrical surface area, we define two types of surface areas, namely the accessible surface area (ASA) and the grain surface area (GSA), analogous to the BET measurements on the sandstone specimen (Luhmann et al., 2014) and the crushed single-mineral grains (Feng-Chih and Clemency, 1981; Stillings and Brantley, 1995; Kalinowski and Schweda, 1996; Richter et al., 2016), respectively. The ASA of individual minerals represents the specific surface are (SSA) of each mineral that is exposed to the pore space in the sandstone. Thus, in Equ. 1, $\rho$ is the rock bulk density $\left(2.11 \mathrm{~g} / \mathrm{cm}^{3}\right)$ and $P$ is the ratio of the pore-mineral interface perimeter to the total image area for the calculation of the ASA. The GSA of individual minerals represents the SSA of the mineral grains in single mineral (here all grain surface areas are accounted for, including the area exposed to pore space and that in contact with other minerals). Therefore, in Equ. 1 . $\rho$ is the corresponding mineral crystal density (listed in Table 1 ) and $P$ is the ratio of the total mineral grain perimeter to the total mineral area of that specific mineral, used to calculate the GSA.

\subsection{Scaling factor (SF) determination: a Monte-Carlo approach}

Compared to the BET measurements of surface area, due to the inherent limits in resolution, the image analysis could not provide enough information on the mineral 
surface roughness for the surface area calculations (Section 3.3). To account for the contribution of surface roughness, we propose surface roughness scaling factors (SF), given by the ratio of the actual physical surface area (usually measured using the BET method) to the image ASA or GSA. It is common that during BET surface area measurements, mono-mineralic samples are ground to a powder with a grain size of 50-200 $\mu \mathrm{m}$ (Feng-Chih and Clemency, 1981; Stillings and Brantley, 1995 Kalinowski and Schweda, 1996; Richter et al., 2016), which is similar to the grain size $(65 \mu \mathrm{m}-250 \mu \mathrm{m})$ of our sandstone sample. Therefore, the GSA of individual minerals in our sandstone sample should yield similar specific surface areas as the SSA of single-mineral grains, measured using the BET method. In this study, the GSAs of individual minerals in the sandstone sample is calculated as the product of the pixel-based contour GSAs from the color-coded SEM image (Figure 2b) and their corresponding SFs. Then we constrain the calculated GSA by the minimum and maximum BET-measured SSAs of the same mineral, reported in previous studies (Table 3), as shown in Equ. 2.

$$
\mathrm{BET}_{i, \text { min }} \leq \mathrm{SF}_{i} \times \mathrm{GSA}_{i} \leq \mathrm{BET}_{i, \text { max }},
$$

where $\mathrm{BET}_{i, \min }$ and $\mathrm{BET}_{i, \max }$ are the lower and upper bounds, respectively, of the reported GSAs of the $i$ th-mineral, measured using the BET method and $\mathrm{GSA}_{i}$ is the pixel-based contour GSA of the $i$ th-mineral calculated from the color-coded SEM image (Figure 2b). In addition, the sum of the ASA of individual minerals in the sandstone sample equals that of the total SSA of the sandstone sample from our BET measurement, $\mathrm{SSA}_{\text {total }}$,

$$
\mathrm{SSA}_{\text {total }}=\sum_{i=1}^{i=N} \mathrm{SF}_{i} \times \mathrm{ASA}_{i},
$$

where $\mathrm{ASA}_{i}$ is the pixel-based contour ASA of the $i$ th-mineral, calculated from the color-coded SEM image (Figure 2b), and $N$ is the total number of minerals in the sandstone (here $N=6$ ). The total SSA of the sandstone is measured using the BET method, as described in Section 2.3 .

$$
\mathrm{BET}_{\text {total,min }} \leq \mathrm{SSA}_{\text {total }} \leq \mathrm{BET}_{\text {total,max }},
$$

where $\mathrm{BET}_{\text {total,min }}=1.6681 \mathrm{~m}^{2} / \mathrm{g}$ and $\mathrm{BET}_{\text {total,max }}=1.6719 \mathrm{~m}^{2} / \mathrm{g}$ are the lower and upper bounds, respectively, of the total SSA, measured by the BET method. Clearly, determining 6 SFs with the above three equations, Equs. 24, 4 results in an under-determined mathematical problem. A common solution for under-determined problems is the Monte-Carlo method. Specifically, we can determine a most probable $\mathrm{SF}$ for each mineral, which satisfies Equs 244. To acquire the most probable SF for each mineral, we have set up a Monte-Carlo method to analyze the probability distributions of all the potential SFs. First, we uniformly generate 100 million random populations of each $\mathrm{SF}_{i}$ of the $i$ th-mineral, under the constraint of Equ. 2, shown as gray-shading in Figure 4. Then, from the randomly generated $\mathrm{SF}_{i}$, we select the 
populations of $\mathrm{SF}_{i}$ that fulfill both Equ. 3 and Equ. 4. Subsequent to the selection of the $\mathrm{SF}_{i}$, the histograms of the six selected $\mathrm{SF}_{i} \mathrm{~s}$ are examined. If the histogram of a selected $\mathrm{SF}_{i}$ shows a nonuniform distribution, this indicates that the $i$ th-mineral dominantly contributes to the total ASA in the sandstone. The mean value of the selected $\mathrm{SF}_{i}$ is taken as the most probable $\mathrm{SF}_{i}$ for the $i$ th mineral, so that this $\mathrm{SF}_{i}$ enters Equ. 3 as a known value. In contrast, when the histogram of a selected $\mathrm{SF}_{i}$ exhibits a uniform distribution, this implies that the ASA of the $i$ th-mineral contributes an insignificant amount to the total ASA of the sandstone, compared to the other minerals, so that in most cases a re-selection process is needed. This reselection of $\mathrm{SF}_{i} \mathrm{~s}$ is carried out for these remaining minerals, using Equs. 3 and 4 , with all the previously determined SFs. We repeat the SF selection process, each time re-examining the histograms, until all SFs are determined. Our selection procedure is illustrated by Figure 4. Note that for minerals that contribute extremely insignificantly to the total ASA (less than the standard deviation of the BET measurement), such as ilmenite in this sandstone, the histograms of the selected SFs can remain uniform (i.e., no populations of the randomly generated SF is filtered out) until the end of the selection. In such cases, the mean value of all SFs within the uniform histogram is taken as the most probable $\mathrm{SF}_{i}$ for this mineral. Finally, we multiply the obtained $\mathrm{SF}_{i}$ by its corresponding mineral $\mathrm{ASA}, \mathrm{ASA}_{i}$, provided by the image analysis (Section 3.3), to derive the actual ASAs of each mineral with the roughness correction at the same resolution of the BET measurements.

\section{Results and discussions}

\subsection{Porosity and pore size distribution}

As we have stated in Section 3.1, choosing an appropriate gray-scale index (GSI) threshold for the binarization of the SEM image is the foundation of further pore space and surface area analyses. Section 3.1 suggests that the image resolution needs to be evaluated during the GSI determination, as a lower image resolution leads to a lower pore fraction (Figure 3b). As suggested by the pore volume calculation, using the mercury intrusion porosimetry data, a GSI threshold of 20 is selected to generate the pore geometry map from the 2D SEM image (Figure 3 a). The pore fraction, calculated from this pore geometry map is $17.5 \%$, which is $20 \%$ lower than the porosity, $21.9 \%$, measured by helium gas pycnometer. This under-estimation of the pore fraction is expected, given the limited image resolution.

Figure 3c shows the pore size distribution (PSD) obtained from the 2D pore geometry map (with a resolution of $1.2 \mu \mathrm{m}$ ), in comparison to the PSD calculated from mercury intrusion measurements and 3D micro-CT scans (with a resolution of $1.1 \mu \mathrm{m})$. The PSD from the 2D image shows a peak in the pore volume at a pore size of $\sim 30 \mu \mathrm{m}$, with a measurable range of $1.2-100 \mu \mathrm{m}$. In contrast, both the mercury porosimetry and the 3D CT results show a pore volume peak at a pore (throat) size of $\sim 15 \mu \mathrm{m}$, with a measurable range of $0.01-100 \mu \mathrm{m}$ and 2.2 $80 \mu \mathrm{m}$, respectively. Both SEM and CT image analyses can largely reproduce the PSD curve, obtained from the mercury intrusion measurement, indicating that the 
GSI threshold of 20 is a suitable threshold for the image processing of this rock specimen. The slight shift in the SEM image PSD results, compared to the 3D PSD results (mercury intrusion and CT data), may be caused by the 2D/3D stereological difference (Münch and Holzer, 2008; Latief, 2016).

\subsection{Specific surface area}

The stereological analysis of the SEM images yields a total SSA (i.e., $\sum \mathrm{ASA}_{i}$ ) of $0.042 \mathrm{~m}^{2} / \mathrm{g}$, while the BET-measured SSA is $1.6700 \pm 0.0019 \mathrm{~m}^{2} / \mathrm{g}$. After the segmentation of mineral phases, the image-based accessible surface area (ASA) for each mineral are calculated and listed in the row of 'ASA from image $\left(\mathrm{m}^{2} / \mathrm{g}\right)$ ' in Table 3. Similarly, the image-based grain surface areas (GSAs) for each mineral are also calculated and documented in the row of 'GSA from image $\left(\mathrm{m}^{2} / \mathrm{g}\right)$ ' in Table 3 . By multiplying the most probable SF, obtained from the Monte-Carlo analysis (the row of 'SF applied to SSA' in Table 3), both the image-based ASA and the GSA can be downscaled to the same resolution as that of the BET measurements. In this study, we term the downscaling ASA and GSA as the corrected ASA (the row of 'Corrected ASA $\left(\mathrm{m}^{2} / \mathrm{g}\right)$ ' in Table 3) and the corrected GSA (the row of 'Corrected GSA $\left(\mathrm{m}^{2} / \mathrm{g}\right)$ ' in Table 3), respectively. As expected, the corrected GSA falls into the range of SSAs for a single mineral, reported by previous studies, using BET measurements on powder (the row of 'GSA from BET Lit. $\left(\mathrm{m}^{2} / \mathrm{g}\right)$ ' in Table 3). The Monte-Carlo algorithm yields the histograms of the SF for the individual minerals, as shown in Figure 4, where the blue shades represent the selected SFs out of the uniformly distributed SFs (gray shades) which are generated randomly. The mean values of the SFs are indicated by the vertical red lines in Figure 4. As stated in Section 3.4, the mean values of the SFs are taken as the most probable SF and used for the ASA and GSA corrections. The order of the SF determination is largely controlled by the mineral's surface area contribution to the total surface area of the rock sample. For example, in our sandstone specimen, the SF of kaolinite is the first one being determined, due to its high image-based ASA and high SSA value reported in its BET measurement. Quartz is the second mineral being determined, because of its large abundance in this sandstone specimen. The order of the SF determination is indicated by the numbers in the up-left corner of each sub-figure in Figure 4. After applying the SF to the ASA of each mineral, we derive a total SSA of $1.67 \mathrm{~m}^{2} / \mathrm{g}$ for the sandstone specimen, the same value as the mean total SSA value provided by the BET measurements. As shown in Table 3, the surface roughness correction significantly increases the surface area fractions of the clay minerals, such as kaolinite. For a mass fraction of $7.9 \%$ in this sandstone specimen, kaolinite provides $81.2 \%$ of the total SSA of the specimen. This is expected, as clay minerals usually accommodate large amounts of micro-features, smaller than the SEM image pixel size $(1.2 \mu \mathrm{m})$. In contrast, quartz only provides $7.3 \%$ of the total SSA, while it comprises 58.4 wt. \% of the specimen. After the correction of surface roughness, the ASAs of muscovite and dolomite are also considerably elevated, compared to their image-based values, due to their flaky and porous features.

However, although the Monte-Carlo algorithm significantly reduces the introduc- 
tion of resolution-induced errors during the ASA estimation, the resolution of the mineral/pore image still plays an important role. The major challenge in processing a relatively low-resolution image lies in the appropriate segmentation of minerals, often leading to poorly described mineral geometry structures and distributions. To illustrate the image resolution effect on the ASA estimation, we calculate the ASA/GSA ratio from images that cover the same area, but which have different resolutions (we resolved the original gray-scale image at resolutions of $2.4 \mu \mathrm{m}, 3.6 \mu \mathrm{m}, 4.8 \mu \mathrm{m}$, and $6.0 \mu \mathrm{m}$, using bicubic interpolation). Due to the coarsening of the pixels, the mineral contours are becoming blurred and the mineral distribution is altered, according to the chosen GSI thresholds for each mineral and applying denoising filters. Table 4 lists the obtained SFs, as well as the resultant ASA and GSA at different image resolutions. The relative differences in the ASAs, with respect to the ASA, obtained with the original image, are plotted in Figure 6. The relative differences for most minerals are still low (less than $25 \%$ ) with resolutions of $2.4 \mu \mathrm{m}$ and $3.6 \mu \mathrm{m}$, as the mineral phases can still be appropriately separated at these resolutions. When the image resolution further decreases to $4.8 \mu \mathrm{m}$, the relative differences for most minerals exhibit a sharp increase. Note that at the resolution of $4.8 \mu \mathrm{m}$, the resultant GSA of kaolinite is already very close to the upper bound of the reported BET measurements $\left(78.0 \mathrm{~m}^{2} / \mathrm{g}\right.$, as shown in Table 3). The high GSA of kaolinite causes concerns regarding the Monte-Carlo algorithm: if no proper SF can be determined for the kaolinite, which exhibits the largest surface area in this sandstone specimen, Equ. 3 will not be satisfied by adjusting the surface areas of the other minerals. For example, when the image resolution is $6.0 \mu \mathrm{m}$ or lower, the Monte-Carlo algorithm could not find any solution for the SF, due to the poorly represented mineral distribution at lower image resolutions.

\subsection{Uncertainty analysis}

It is known that solutions of the Monte-Carlo analysis might be affected by the choice of randomness and the population size. To understand the uncertainty of our Monte-Carlo analysis in this study, we examine the sensitivity of the mean value and standard deviation (std) of the calculated SF on the SF population size. We thus randomly generate groups of SFs with various population sizes, from $1 \times 10^{5}$, $5 \times 10^{5}, 1 \times 10^{6}, 5 \times 10^{6}, 1 \times 10^{7}, 5 \times 10^{7}$, to $1 \times 10^{8}$. For each population size, we consider two scenarios, one with 100 and one with 1000 realizations, to calculate the mean value and the standard deviation of the SF. As shown in Figure 5, the change in realization number (from 100 to 1000) does not affect the mean value or the standard deviation of the calculated SF, indicating a sufficiently large realization number for the uncertainty analysis. The population size does not affect the mean value of the $\mathrm{SF}$ either. However, a larger population size reduces the standard deviation of the calculated SF. In this study, the Monte-Carlo calculation with a population size of $1 \times 10^{8}$ at 1000 realizations is used as a reference scenario, from which the mean value is used to correct the ASAs (Table 3), where the standard deviation is reported as the uncertainty (Figure 4). 

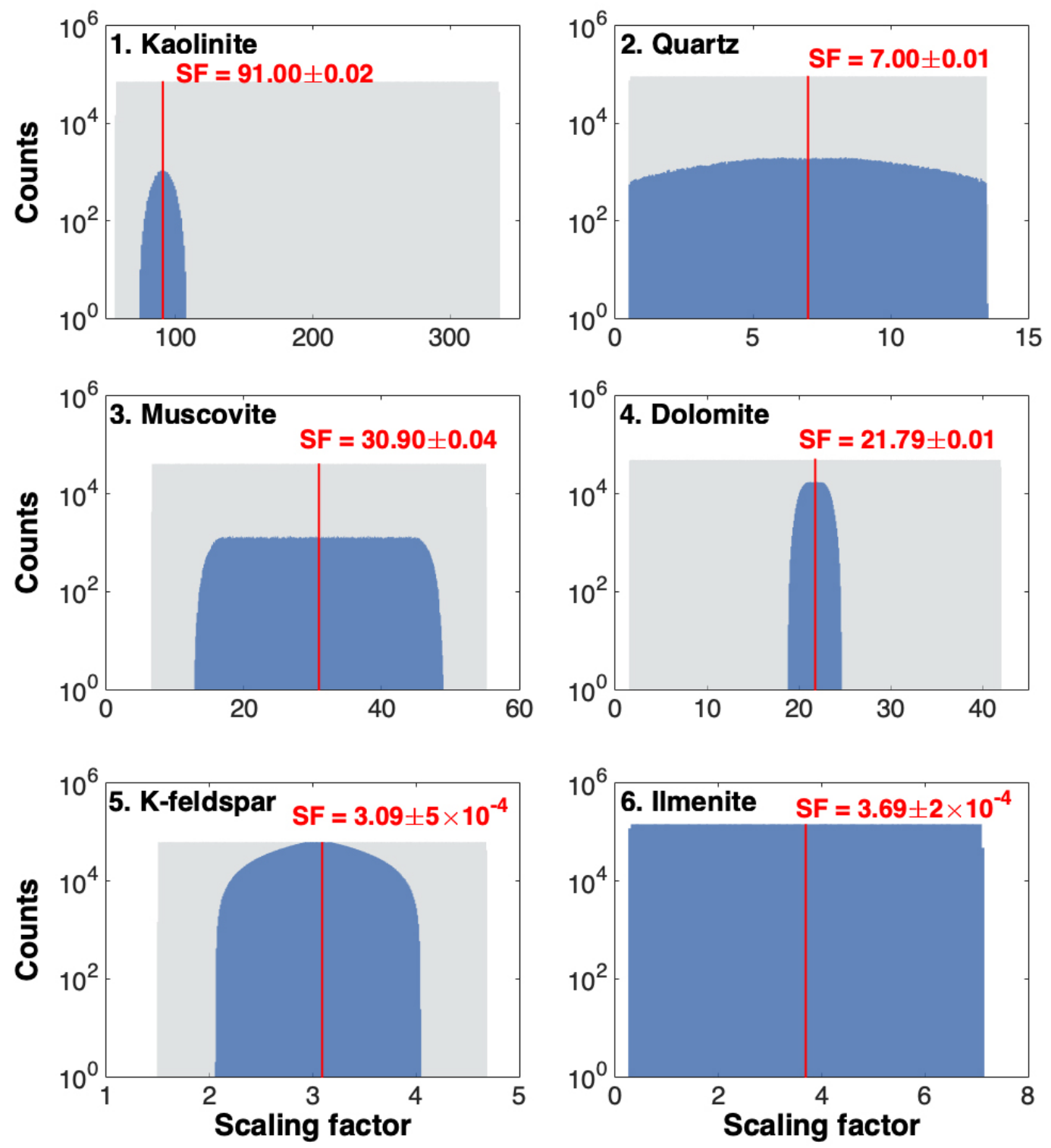

Figure 4: Roughness scaling factors (SFs), obtained by the Monte-Carlo algorithm. The gray shade represents the uniformly-distributed SFs, generated by a uniform random process with the constraint of Equ. 2. The blue shade represents the distribution of the selected SF, i.e., the MonteCarlo solutions to Equs. 3 and 4 . The red vertical lines indicate the mean of the selected SFs. The numbers in the upper-left corners in each panel indicates the determination order of the SFs. 


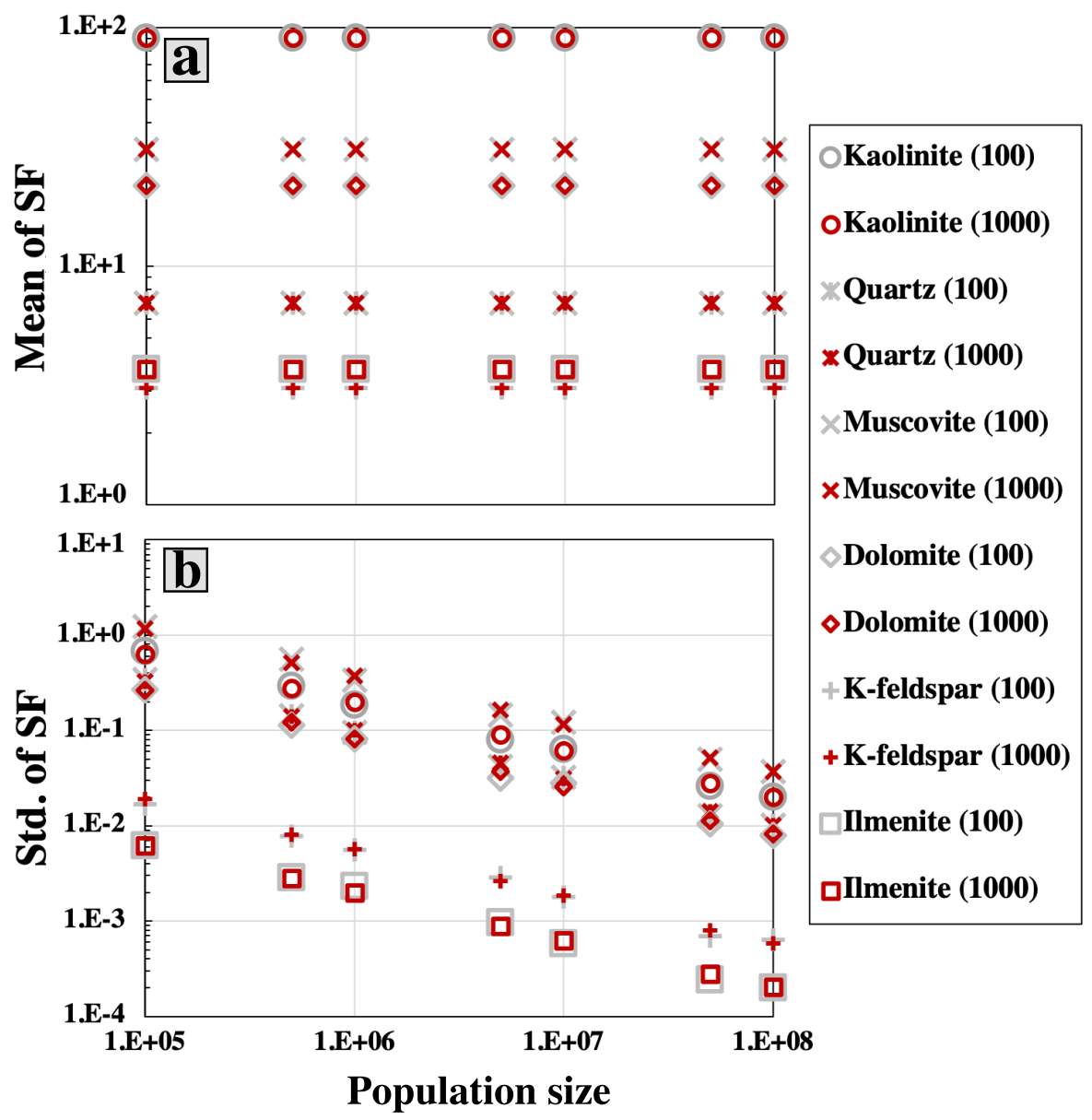

Figure 5: (a) Mean values and (b) standard deviations of scaling factors (SFs), based on two scenarios, one with 100 (in gray) and one with 1000 (in red) realizations. Each scenario is performed with SF population sizes from $10^{5}$ to $10^{8}$. 


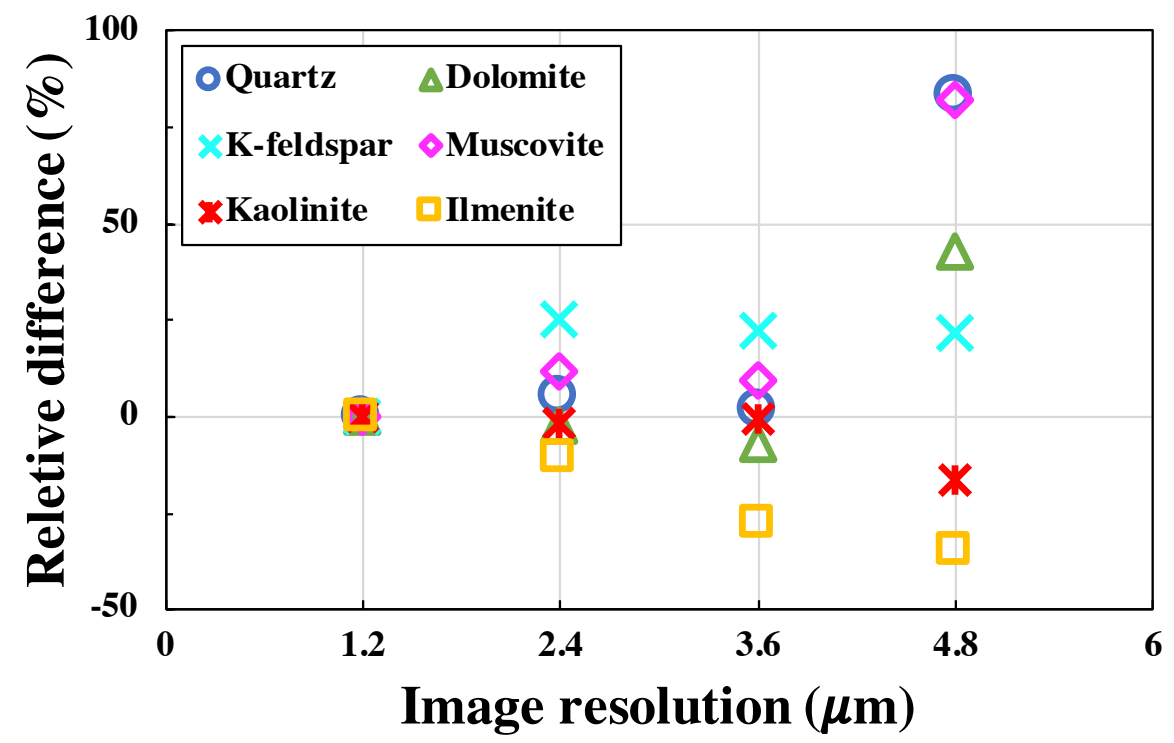

Figure 6: Relative differences $(\times 100 \%)$ in the determined ASAs for different image resolutions, compared to the original image resolution $(1.2 \mu \mathrm{m})$.

\section{Conclusions}

This study introduces an image-based method to quantify the accessible surface area (ASA) of each individual mineral in a multi-mineral natural rock. A MonteCarlo algorithm is developed to determine the most probable surface roughness scaling factor (SF) for each mineral, with the support of BET measurements. This Monte-Carlo method enables us to downscale the image pixel/voxel resolution to the BET resolution at the atomic level and, thus, reduces the ASA estimation error, induced by the limits of image resolution. With the application of this method, the ASA can be determined at sufficiently high precision (i.e., at the BET resolution), which is beneficial for both reactive transport experiments and numerical modelling.

This surface area correction approach is particularly important in studies of chemical surface reactions. As reported in previous reactive transport experiments et al., 2015; Beckingham et al., 2017; Al-Khulaifi et al., 2018), the effective reactive surface area is usually one or two orders of magnitude smaller than the physical ASA, likely due to heterogeneous pore-scale mass transport. To infer the effective reactive surface area of the dolomite in this sandstone, the here calculated ASA of this dolomite (Table 3) is used to post-process a reactive transport experiment results (Ma et al., 2019). During the experiment, a $0.8 \mathrm{~mol} / \mathrm{L} \mathrm{CO}_{2}$-enriched brine is circulated at a constant rate of $2 \mathrm{ml} / \mathrm{min}$. Our geochemical reaction calculations suggest a low dolomite surface efficiency of $1.36 \%$. This efficiency is later validated by a stochastic model performed on the SEM image shown in Figure $2 \mathrm{~b}$ (Ma et al. 2019). We, therefore, conclude that our joint method can effectively estimate the ASAs of individual minerals at atomic scales. 
Table 3: Surface roughness correction for the GSA and ASA values from the SEM image analysis, based on surface area measurements, using the BET method. The literature data are for BETmeasured GSA values of single minerals (in powder): quartz (Qtz.) (Tester et al., 1994; NavarreSitchler et al., 2013; Zhang et al., 2015), dolomite (Dol.) (Pokrovsky et al., 2005: Zhang et al., 2014), K-feldspar (Kfs.) (Stillings and Brantley, 1995; Richter et al., 2016), muscovite (Mu.) (Feng-Chih and Clemency, 1981: Kalinowski and Schweda, 1996: Richter et al., 2016), and kaolinite (Kln.) (Wieland and Stumm, 1992, Devidal et al., 1997; Dawodu and Akpomie, 2014, Hai et al., 2015, Tan et al. |2017).

\begin{tabular}{|c|c|c|c|c|c|c|c|}
\hline & Qtz. & Dol. & Kfs. & Mu. & Kln. & Ilm. & Total \\
\hline $\begin{array}{l}\text { GSA from } \\
\text { image }\left(\mathrm{m}^{2} / \mathrm{g}\right)\end{array}$ & 0.041 & 0.047 & 0.053 & 0.100 & 0.232 & 0.078 & \\
\hline $\begin{array}{l}\text { ASA from } \\
\text { image }\left(\mathrm{m}^{2} / \mathrm{g}\right)\end{array}$ & 0.0173 & 0.0030 & 0.0034 & 0.0038 & 0.0149 & 0.0004 & 0.042 \\
\hline $\begin{array}{l}\text { GSA from } \\
\text { BET Lit. } \\
\left(\mathrm{m}^{2} / \mathrm{g}\right)\end{array}$ & $\begin{array}{l}0.02- \\
0.55\end{array}$ & $\begin{array}{l}0.07- \\
1.96\end{array}$ & $\begin{array}{l}0.08- \\
0.25\end{array}$ & $\begin{array}{l}0.66- \\
5.53\end{array}$ & $\begin{array}{l}13.2- \\
78.0\end{array}$ & & \\
\hline $\begin{array}{l}\text { SF applied to } \\
\text { SSA }\end{array}$ & 7.00 & 21.79 & 3.09 & 30.90 & 91.00 & 3.69 & \\
\hline $\begin{array}{l}\text { Corrected } \\
\text { GSA }\left(\mathrm{m}^{2} / \mathrm{g}\right)\end{array}$ & 0.287 & 1.024 & 0.164 & 3.090 & 21.112 & 0.288 & \\
\hline $\begin{array}{l}\text { Corrected } \\
\text { ASA }\left(\mathbf{m}^{2} / g\right)\end{array}$ & 0.121 & 0.065 & 0.011 & 0.117 & 1.356 & 0.001 & 1.670 \\
\hline $\begin{array}{l}\text { ASA fraction } \\
(\%)\end{array}$ & 7.25 & 3.89 & 0.66 & 7.01 & 81.20 & 0.06 & \\
\hline
\end{tabular}

\section{Acknowledgement}

This work is supported by a European research project, entitled Demonstration of soft stimulation treatments of geothermal reservoirs (DESTRESS), funded by the European Union's Horizon 2020 research and innovation programme under the Grant Agreement No. 691728. The rock specimen was provided by Geoterma, a Lithuanian geothermal energy company. The XRCT scan and the corresponding PSD analysis of the specimen were performed by Duncan Webster at SCANCO Medical, Bruettisellen, Switzerland. The specimen porosity was measured in the Rock deformation laboratory at ETH Zürich with the help of Dr. Claudio Madonna. The specimen SEM analysis was performed in the high-pressure lab at ETH Zürich with the help of Dr. Eric Reusser. We also thank the Werner Siemens-Stiftung (Werner Siemens Foundation) for its support of the Geothermal Energy and Geofluids (GEG.ethz.ch) Group at ETH Zürich, Switzerland. 
Table 4: ASA and GSA calculations at different image resolutions.

\begin{tabular}{|c|c|c|c|c|c|c|c|}
\hline & Qtz. & Dol. & Kfs. & Mu. & Kln. & Ilm. & Total \\
\hline \multicolumn{8}{|c|}{ Image resolution $1.2 \mu \mathrm{m}$ (original) } \\
\hline SF & 7.00 & 21.79 & 3.09 & 30.90 & 91.00 & 3.69 & \\
\hline $\operatorname{GSA}\left(\mathrm{m}^{2} / \mathrm{g}\right)$ & 0.287 & 1.024 & 0.164 & 3.090 & 21.112 & 0.288 & \\
\hline $\operatorname{ASA}\left(\mathrm{m}^{2} / \mathrm{g}\right)$ & 0.121 & 0.065 & 0.011 & 0.117 & 1.356 & 0.001 & 1.670 \\
\hline \multicolumn{8}{|c|}{ Image resolution $2.4 \mu \mathrm{m}$} \\
\hline SF & 4.05 & 12.77 & 1.92 & 17.95 & 113.51 & 2.63 & \\
\hline $\operatorname{GSA}\left(\mathrm{m}^{2} / \mathrm{g}\right)$ & 0.280 & 1.014 & 0.166 & 2.990 & 36.555 & 0.284 & \\
\hline $\operatorname{ASA}\left(\mathrm{m}^{2} / \mathrm{g}\right)$ & 0.128 & 0.063 & 0.013 & 0.131 & 1.334 & 0.001 & 1.670 \\
\hline \multicolumn{8}{|c|}{ Image resolution $3.6 \mu \mathrm{m}$} \\
\hline SF & 2.88 & 9.58 & 1.43 & 12.33 & 164.10 & 2.28 & \\
\hline $\operatorname{GSA}\left(\mathrm{m}^{2} / \mathrm{g}\right)$ & 0.279 & 1.039 & 0.166 & 2.984 & 65.013 & 0.285 & \\
\hline $\operatorname{ASA}\left(\mathrm{m}^{2} / \mathrm{g}\right)$ & 0.123 & 0.061 & 0.013 & 0.128 & 1.345 & 0.001 & 1.670 \\
\hline \multicolumn{8}{|c|}{ Image resolution $4.8 \mu \mathrm{m}$} \\
\hline SF & 4.09 & 12.25 & 1.00 & 16.20 & 176.30 & 2.00 & \\
\hline $\operatorname{GSA}\left(\mathrm{m}^{2} / \mathrm{g}\right)$ & 0.518 & 1.711 & 0.163 & 5.177 & 77.580 & 0.286 & \\
\hline $\operatorname{ASA}\left(\mathrm{m}^{2} / \mathrm{g}\right)$ & 0.222 & 0.093 & 0.013 & 0.213 & 1.129 & 0.001 & 1.670 \\
\hline
\end{tabular}

\section{References}

Adams B. M., Kuehn T. H., Bielicki J. M., Randolph J. B. and Saar M. O. (2015). A comparison of electric power output of $\mathrm{CO}_{2}$ Plume Geothermal (CPG) and brine geothermal systems for varying reservoir conditions. Applied Energy, 140, $365-377$.

Al-Khulaifi Y., Lin Q., Blunt M. J. and Bijeljic B. (2018). Reservoir-condition porescale imaging of dolomite reaction with supercritical $\mathrm{CO}_{2}$ acidified brine: Effect of pore-structure on reaction rate using velocity distribution analysis. International Journal of Greenhouse Gas Control, 68, 99-111.

Althaus E. and Edmunds W. (1987). Geochemical research in relation to hot dry rock geothermal systems. Geothermics, 16, 451-458.

Beckingham L. E., Mitnick E. H., Steefel C. I., Zhang S., Voltolini M., Swift A. M., Yang L., Cole D. R., Sheets J. M., Ajo-Franklin J. B. et al. (2016). Evaluation of mineral reactive surface area estimates for prediction of reactivity of a multimineral sediment. Geochimica et Cosmochimica Acta, 188, 310-329.

Beckingham L. E., Steefel C. I., Swift A. M., Voltolini M., Yang L., Anovitz L. M., Sheets J. M., Cole D. R., Kneafsey T. J., Mitnick E. H. et al. (2017). Evaluation of 
accessible mineral surface areas for improved prediction of mineral reaction rates in porous media. Geochimica et Cosmochimica Acta, 205, 31-49.

Bourg I. C., Beckingham L. E. and DePaolo D. J. (2015). The nanoscale basis of $\mathrm{CO}_{2}$ trapping for geologic storage. Environmental Science 83 Technology, 49 , 10265-10284.

Brehme M., Regenspurg S., Leary P., Bulut F., Milsch H., Petrauskas S., Valickas R. and Blöcher G. (2018). Injection-triggered occlusion of flow pathways in geothermal operations. Geofluids, 2018.

Brunauer S., Emmett P. H. and Teller E. (1938). Adsorption of gases in multimolecular layers. Journal of the American Chemical Society, 60, 309-319.

Cai R., Lindquist W. B., Um W. and Jones K. W. (2009). Tomographic analysis of reactive flow induced pore structure changes in column experiments. Advances in Water Resources, 32, 1396-1403.

Cheshire M. C., Stack A. G., Carey J. W., Anovitz L. M., Prisk T. R. and Ilavsky J. (2016). Wellbore cement porosity evolution in response to mineral alteration during $\mathrm{CO}_{2}$ flooding. Environmental Science \&3 Technology, 51, 692-698.

Cubillas P., Köhler S., Prieto M., Chaïrat C. and Oelkers E. H. (2005). Experimental determination of the dissolution rates of calcite, aragonite, and bivalves. Chemical Geology, 216, 59-77.

Dawodu F. A. and Akpomie K. G. (2014). Simultaneous adsorption of Ni (II) and Mn (II) ions from aqueous solution unto a Nigerian kaolinite clay. Journal of Materials Research and Technology, 3, 129-141.

Devidal J.-L., Schott J. and Dandurand J.-L. (1997). An experimental study of kaolinite dissolution and precipitation kinetics as a function of chemical affinity and solution composition at $150{ }^{\circ} \mathrm{C}, 40$ bars, and $\mathrm{pH}$ 2, 6.8, and 7.8. Geochimica et Cosmochimica Acta, 61, 5165-5186.

Dogan A. U., Dogan M., Onal M., Sarikaya Y., Aburub A. and Wurster D. E. (2006). Baseline studies of the Clay Minerals Society source clays: specific surface area by the Brunauer Emmett Teller (BET) method. Clays and Clay Minerals, 54, 62-66.

Ellis B. R. and Peters C. A. (2016). 3D mapping of calcite and a demonstration of its relevance to permeability evolution in reactive fractures. Advances in Water Resources, 95, 246-253.

Feng-Chih L. and Clemency C. V. (1981). The kinetics of dissolution of muscovites at $25^{\circ} \mathrm{C}$ and $1 \mathrm{~atm} \mathrm{CO}_{2}$ partial pressure. Geochimica et Cosmochimica Acta, 45, $571-576$. 
Garapati N., Randolph J. B. and Saar M. O. (2015). Brine displacement by $\mathrm{CO}_{2}$, energy extraction rates, and lifespan of a $\mathrm{CO}_{2}$-limited $\mathrm{CO}_{2}$-Plume Geothermal (CPG) system with a horizontal production well. Geothermics, 55, 182-194.

Gaus I. (2010). Role and impact of $\mathrm{CO}_{2}$-rock interactions during $\mathrm{CO}_{2}$ storage in sedimentary rocks. International Journal of Greenhouse Gas Control, 4, 73-89.

Gunter W., Perkins E. and Hutcheon I. (2000). Aquifer disposal of acid gases: modelling of water-rock reactions for trapping of acid wastes. Applied Geochemistry, 15, 1085-1095.

Hai Y., Li X., Wu H., Zhao S., Deligeer W. and Asuha S. (2015). Modification of acid-activated kaolinite with $\mathrm{TiO}_{2}$ and its use for the removal of azo dyes. Applied Clay Science, 114, 558-567.

Hildebrand T. and Rüegsegger P. (1997). A new method for the model-independent assessment of thickness in three-dimensional images. Journal of Microscopy, 185, $67-75$.

Kalinowski B. E. and Schweda P. (1996). Kinetics of muscovite, phlogopite, and biotite dissolution and alteration at $\mathrm{pH} 1-4$, room temperature. Geochimica et Cosmochimica Acta, 60, 367-385.

Knauss K. G., Johnson J. W. and Steefel C. I. (2005). Evaluation of the impact of $\mathrm{CO}_{2}$, co-contaminant gas, aqueous fluid and reservoir rock interactions on the geologic sequestration of $\mathrm{CO}_{2}$. Chemical Geology, 217, 339-350.

Kweon H. and Deo M. (2017). The impact of reactive surface area on brine-rockcarbon dioxide reactions in $\mathrm{CO}_{2}$ sequestration. Fuel, 188, 39-49.

Lai P., Moulton K. and Krevor S. (2015). Pore-scale heterogeneity in the mineral distribution and reactive surface area of porous rocks. Chemical Geology, 411, 260-273.

Landrot G., Ajo-Franklin J. B., Yang L., Cabrini S. and Steefel C. I. (2012). Measurement of accessible reactive surface area in a sandstone, with application to $\mathrm{CO}_{2}$ mineralization. Chemical Geology, 318, 113-125.

Latief F. (2016). Analysis and Visualization of 2D and 3D Grain and Pore Size of Fontainebleau Sandstone Using Digital Rock Physics. In Journal of Physics: Conference Series (p. 012047). IOP Publishing volume 739.

Li L., Peters C. A. and Celia M. A. (2006). Upscaling geochemical reaction rates using pore-scale network modeling. Advances in Water Resources, 29, 1351-1370.

Luhmann A. J., Kong X.-Z., Tutolo B. M., Garapati N., Bagley B. C., Saar M. O. and Seyfried Jr W. E. (2014). Experimental dissolution of dolomite by $\mathrm{CO}_{2}$-charged brine at $100{ }^{\circ} \mathrm{C}$ and 150 bar: Evolution of porosity, permeability, and reactive surface area. Chemical Geology, 380, 145-160. 
Ma J., Querci L., Hattendorf B., Saar M. O. and Kong X.-Z. (2019). Towards a spatio-temporal understanding on dolomite dissolution in sandstone by $\mathrm{CO}_{2-}$ enriched brine circulation. Environmental Science 83 Technology, . In revision.

Menke H. P., Bijeljic B., Andrew M. G. and Blunt M. J. (2015). Dynamic threedimensional pore-scale imaging of reaction in a carbonate at reservoir conditions. Environmental Science \& Technology, 49, 4407-4414.

Münch B. and Holzer L. (2008). Contradicting geometrical concepts in pore size analysis attained with electron microscopy and mercury intrusion. Journal of the American Ceramic Society, 91, 4059-4067.

Navarre-Sitchler A. K., Cole D. R., Rother G., Jin L., Buss H. L. and Brantley S. L. (2013). Porosity and surface area evolution during weathering of two igneous rocks. Geochimica et Cosmochimica Acta, 109, 400-413.

Nogues J. P., Fitts J. P., Celia M. A. and Peters C. A. (2013). Permeability evolution due to dissolution and precipitation of carbonates using reactive transport modeling in pore networks. Water Resources Research, 49, 6006-6021.

Noiriel C., Luquot L., Madé B., Raimbault L., Gouze P. and Van Der Lee J. (2009). Changes in reactive surface area during limestone dissolution: An experimental and modelling study. Chemical Geology, 265, 160-170.

Pandey S., Chaudhuri A., Rajaram H. and Kelkar S. (2015). Fracture transmissivity evolution due to silica dissolution/precipitation during geothermal heat extraction. Geothermics, 57, 111-126.

Peters C. A. (2009). Accessibilities of reactive minerals in consolidated sedimentary rock: An imaging study of three sandstones. Chemical Geology, 265, 198-208.

Pokrovsky O. S., Golubev S. V. and Schott J. (2005). Dissolution kinetics of calcite, dolomite and magnesite at $25{ }^{\circ} \mathrm{C}$ and 0 to 50 atm $\mathrm{pCO}_{2}$. Chemical Geology, 217, 239-255.

Qin F. and Beckingham L. E. (2018). Impact of image resolution on quantification of mineral distribution and accessible surface areas. In AGU Fall Meeting Abstracts.

Richter C., Müller K., Drobot B., Steudtner R., Großmann K., Stockmann M. and Brendler V. (2016). Macroscopic and spectroscopic characterization of uranium (VI) sorption onto orthoclase and muscovite and the influence of competing $\mathrm{Ca}^{2+}$. Geochimica et Cosmochimica Acta, 189, 143-157.

Saar M. O., Randolph J. B. and Kuehn T. H. (2012). The Regents of the University of Minnesota. Carbon dioxide-based geothermal Energy generation systems and methods related thereto. US Patent 8,316,955. 
Stillings L. L. and Brantley S. L. (1995). Feldspar dissolution at $25^{\circ} \mathrm{C}$ and $\mathrm{pH} 3$ : Reaction stoichiometry and the effect of cations. Geochimica et Cosmochimica Acta, 59, 1483-1496.

Tan X., Liu G., Mei H., Fang M., Ren X. and Chen C. (2017). The influence of dissolved $\mathrm{Si}$ on $\mathrm{Ni}$ precipitate formation at the kaolinite water interface: Kinetics, DRS and EXAFS analysis. Chemosphere, 173, 135-142.

Tester J. W., Worley W. G., Robinson B. A., Grigsby C. O. and Feerer J. L. (1994). Correlating quartz dissolution kinetics in pure water from 25 to $625^{\circ} \mathrm{C}$. Geochimica et Cosmochimica Acta, 58, 2407-2420.

Tutolo B. M., Luhmann A. J., Kong X.-Z., Saar M. O. and Seyfried Jr W. E. (2015). $\mathrm{CO}_{2}$ sequestration in feldspar-rich sandstone: coupled evolution of fluid chemistry, mineral reaction rates, and hydrogeochemical properties. Geochimica et Cosmochimica Acta, 160, 132-154.

Voskov D. V., Henley H. and Lucia A. (2017). Fully compositional multi-scale reservoir simulation of various $\mathrm{CO}_{2}$ sequestration mechanisms. Computers \& Chemical Engineering, 96, 183-195.

Weibel E. R. (1969). Stereological principles for morphometry in electron microscopic cytology1. In International Review of Cytology (pp. 235-302). Elsevier volume 26.

White S., Allis R., Moore J., Chidsey T., Morgan C., Gwynn W. and Adams M. (2005). Simulation of reactive transport of injected $\mathrm{CO}_{2}$ on the Colorado Plateau, Utah, USA. Chemical Geology, 217, 387-405.

Wieland E. and Stumm W. (1992). Dissolution kinetics of kaolinite in acidic aqueous solutions at $25^{\circ} \mathrm{C}$. Geochimica et Cosmochimica Acta, 56, 3339-3355.

Xu T., Apps J. A. and Pruess K. (2003). Reactive geochemical transport simulation to study mineral trapping for $\mathrm{CO}_{2}$ disposal in deep arenaceous formations. Journal of Geophysical Research: Solid Earth, 108.

Xu T., Apps J. A. and Pruess K. (2004). Numerical simulation of $\mathrm{CO}_{2}$ disposal by mineral trapping in deep aquifers. Applied Geochemistry, 19, 917-936.

Yasuhara H., Kinoshita N., Lee D. S., Choi J. and Kishida K. (2017). Evolution of mechanical and hydraulic properties in sandstone induced by simulated mineral trapping of $\mathrm{CO}_{2}$ geo-sequestration. International Journal of Greenhouse Gas Control, 56, 155-164.

Zhang R., Zhang X. and Hu S. (2015). Dissolution kinetics of quartz in water at high temperatures across the critical state of water. The Journal of Supercritical Fluids, 100, 58-69.

Zhang X., Glasser F. and Scrivener K. (2014). Reaction kinetics of dolomite and portlandite. Cement and Concrete Research, 66, 11-18. 